\title{
Cranial autonomic symptoms in episodic migraine: An observational study from headache clinic of a tertiary care center of North India
}

\author{
Abdul Qavi $D M^{1}$ (D), Pradeep Kumar Maurya $D M^{2}$ (D), Rajani Bala Jasrotia $M D^{3}$ iD, Ajai Kumar Singh $D M^{4}$ (D), \\ Dinkar Kulshreshtha $D M^{5}$ iD, Arshi Ansari $M D^{6}$ iD, Anup Kumar Thacker $D M^{7}$ iD \\ 1,2,3,4,5,6,7 Dr Ram Manohar Lohia Institute of Medical Sciences, Lucknow, India
}

Date of submission: $24^{\text {th }}$ February 2021

Date of acceptance: $16^{\text {th }}$ August 2021

Date of publication: $1^{\text {st }}$ September 2021

\begin{abstract}
Introduction: The presence of cranial autonomic symptoms (CAS) is a hallmark of trigeminal autonomic cephalalgia like cluster headache but their presence in migraine is also not uncommon. Like in trigeminal autonomic cephalalgias, the activation of the trigeminal autonomic reflex pathway is thought to be the possible explanation of the presence of cranial autonomic symptoms in migraine also. Previous studies suggested that around half of the patients of migraine suffer from these symptoms. The aim of our study was to observe the frequency of cranial autonomic symptoms in episodic migraine patients along with their clinical and autonomic characteristics.

Methods and Materials: Fifty patients of episodic migraine attending the headache clinic of Dr. RMLIMS, Lucknow and fulfilling the diagnostic criteria of International classification of headache disorder third edition beta were randomly selected and enrolled in the study. The detailed interview regarding presence of cranial autonomic symptoms was recorded along with the clinical characteristics, demographic features and autonomic profile of the migraine patients.
\end{abstract}

Results: About three-fourth (72\%) of the patients were females. The mean age of study participants was $27.7 \pm 8.3$ years. A considerable number of patients (54\%) had a long duration (5-10 years) of illness and $70 \%$ of patients had severe headaches. Photophobia was the most common (88\%) associated clinical symptoms while lacrimation was the most common (56\%) cranial autonomic symptom in migraine patients. Among 50 patients of migraine $74 \%$ of patients were having at least one cranial autonomic symptoms.

Conclusion: Cranial autonomic symptoms are common in patients of episodic migraine. More severe headache is more likely to be associated with the development of cranial autonomic symptoms.

Key words: Cranial autonomic symptoms, Episodic migraine, Migraine, Parasympathetic cranial autonomic symptoms, Systemic autonomic symptoms, Trigeminal autonomic reflex.

Access this article online

Website: https://www.nepjol.info/index.php/NJN

DOI: https://doi.org/10.3126/njn.v18i3.35069

HOW TO CITE

Qavi A, Maurya PK, Jasrotia RB, Singh AK, Kulshreshtha D, Ansari A, Thacker AK. Cranial autonomic symptoms in episodic migraine: An observational study from headache clinic of a tertiary care center of North India. NJNS. 2021;18(3):28-34.

Address for correspondence:

Dr. Abdul Qavi

Department of Neurology,

Dr Ram Manohar Lohia Institute of Medical Sciences,

Gomtinagar, Lucknow, India

E-mail: drqavi2008@gmail.com

Phone: +91-9450417111

Copyright (C) 2021 Nepalese Society of Neurosurgeons (NESON)

ISSN: 1813-1948 (Print), 1813-1956 (Online)

This work is licensed under a Creative Commons Attribution-Non Commercial 4.0 International License.

\section{Introduction}

igraine, a common primary headache disorder, is one of the most common neurological ailments of modern society and possesses a significant impact on a patient's life. Migraine is more prevalent in younger age groups especially in females. ${ }^{1,2}$ According to International classification of headache disorder third edition beta, Primary headache disorders classified as Migraine, Tension type headache, Trigeminal Autonomic Cephalalgias and other primary headache disorders like New Daily Persistent Headache (NDPH). ${ }^{3}$ Though migraine is primarily a disorder of cranium but some systemic manifestations of autonomic nervous system involvement including coldness in the extremities, paroxysmal tachycardia gastrointestinal involvement in the form of nausea, diarrhea, and constipation, are present in these patients of primary headache. ${ }^{4}$ In some previous studies it was also found that migraine is associated with sympathetic and parasympathetic hypofunction, hyper function or sympathetic instability. ${ }^{5,6}$ 
Trigeminal autonomic cephalalgias (TACs) such as cluster headache and paroxysmal hemicranias are primary headache disorder typically characterized by cranial autonomic symptoms (CAS) like conjunctival injection, lacrimation, nasal congestion etc. but these CAS were seen in substantial cases of migraine also. ${ }^{6-9}$ Various mechanisms has been postulated to explain the pathophysiology of migraine among which activation of Trigemino-Vascular system and sensitization of trigeminal brainstem nuclei is proposed to be possible basic mechanism. Extra cranial and intracranial arteries, as well as afferent fibers of nociceptive transmission are innervated by sensory inputs of trigeminal nerve. ${ }^{10}$ In the previous animal and human experimental studies also, the contribution of trigemino vascular system has been detected in the pathogenesis of migraine. ${ }^{10,11}$

Due to involvement of the trigeminal vascular system in the pathogenesis of migraine, CAS are expected in migraine also as seen in TACs. In previous studies done so far, CAS were present in a range of $26.9 \%$ to $82 \%$ in patients of migraine. ${ }^{12,13}$ These CAS in migraine are present in both - migraine with aura and migraine without aura $;{ }^{7}$ can be either unilateral ${ }^{14}$ or bilateral ${ }^{15}$ or sometimes side locked. ${ }^{16}$ Some recent researches and studies, suggested that CAS is a common constituent of migraine and it is not an exception. ${ }^{17,18}$

Sometimes the presence of these cranial and systemic autonomic symptoms creates problems in diagnosis and management of this headache disorder. Misdiagnosis with sinus headache is common in this regard, culminating in sinus surgery with no relief of these symptoms. ${ }^{19,20}$ As migraine is one of the most common neurological disorders, the understanding of prevalence of CAS in migraine is necessary for proper diagnosis and management.

Therefore the present study is aimed to know the frequency of CAS, type of cranial autonomic symptoms with their frequency and aggravating factors in the patients of migraine.

\section{Methods and Materials}

This was a cross sectional observational study conducted in the Department of Neurology Dr. Ram Manohar Lohia Institute of Medical Sciences, Lucknow, India. The ethical approval was taken from institutional ethics committee (IEC No. 26/17) and written informed consent was obtained from all the participants. Total 50 patients with migraine were enrolled in the study. These patients were seen in the headache clinic of Neurology OPD, Dr. RMLIMS from June 2018 to November 2019

\section{Inclusion Criteria}

1. Cases of episodic migraine were selected according to International classification of headache disorder third edition beta.
2. Patients with all age groups.

\section{Exclusion Criteria}

1. Patients with secondary headaches.

2. Evidence of systemic illness such as DM, HTN, Hypothyroidism, primary malignancy, neuropathy, medical comorbidities, other chronic infections.

3. Patients on medication overuse headache.

4. Denial of consent.

\section{Data collection and Analysis of cranial autonomic symptoms and aggravating factors}

A pre-designed semi-structured schedule was used for data collection. Information was collected regarding the presence of CAS along with the clinical characteristics and demographic and autonomic profile of the migraine patients. Clinical characteristics like headache severity, duration and other characters as defined by ICHD-3 (Beta version) guidelines of migraine were assessed. Cranial autonomic symptoms like Conjunctival injection, Lacrimation, Nasal congestion, Rhinorrhea, Eyelid edema, Forehead and facial sweating, Forehead and facial flushing, Sensation of fullness or pressure in the ear, Miosis and Ptosis were asked as leading questions. As some of the CAS like miosis can be missed by patient or attendants, so they were advised to come in OPD with the photograph/video of face during ictal (headache) period. Information regarding headache location (global, alternating hemicranial, bifrontal, bitemporal, occipital, either as bilateral presence or unilateral) and aggravating factors of migraine (sunlight, noise, fasting, travel and stress) were also assessed.

\section{Statistical Analysis}

Statistical analysis was done by using SPSS version 16.0 version (Chicago, Inc, USA). Quantitative data was represented as mean $\pm \mathrm{SD}$ and qualitative data was represented as frequencies along with their percentages. Graphs and charts were used as and when required, for better representation of the data. Association between categorical variables was tested using the Chi-Square test. A ' $p$ ' value less than 0.05 was considered statistically significant.

\section{Results}

The present study was conducted among 50 patients of migraine fulfilling ICHD 3 (beta version) criteria.

\section{Demographic profile of Cases}

About three-fourths (72\%) of migraine patients were females while almost half $(42 \%)$ were in the age group of 15-25 years. The mean age of migraine patients was $27.7 \pm 8.3$ years. Forty six per cent of the patients belonged 


\section{Qavi et al}

to urban localities. Family history of migraine was present in $28 \%$ of the cases.

\section{Clinical Characteristics of headache of cases}

A substantial number of patients (54\%) had a long duration (5-10 years) of illness. while $62 \%$ had about 5-10 episodes of headache every month. Majority of patients had hemi cranial headache $(76 \%)$ and seventy percent had severe headache. Among associated symptoms photophobia was most common (88\%) while vertigo was among $24 \%$ only. Sunlight was found to be the most common (90\%) aggravating feature followed by noise (74\%) while stress and travel aggravates headache in $18 \%$ of patients only.

\section{Cranial autonomic symptoms in migraine cases}

About three fourths $(74 \%)$ had at least one of cranial autonomic symptoms. Basic demographic features were almost equally distributed among CAS + and CAS groups. In individual analysis of CAS, lacrimation (56\%) was the most common symptom followed by eyelid edema (46\%), facial sweating (36\%), facial flushing (32\%), aural fullness (26\%), conjunctival injection (24\%), nasal congestion $(12 \%)$, and ptosis $(8 \%)$. None of the patients had rhinorrhea and miosis/ mydriasis as CAS (Figure 1).

The most frequent cranial autonomic symptom was lacrimation, reported in $56 \%$ of the patients, followed by eyelid edema. Around half of the patients (47\%) among CAS + group had at least one or two CAS while $53 \%$ patients had three or more CAS in CAS+ group. No patient in our cohort had CAS symptoms in more than five in number individually (Figure 2).

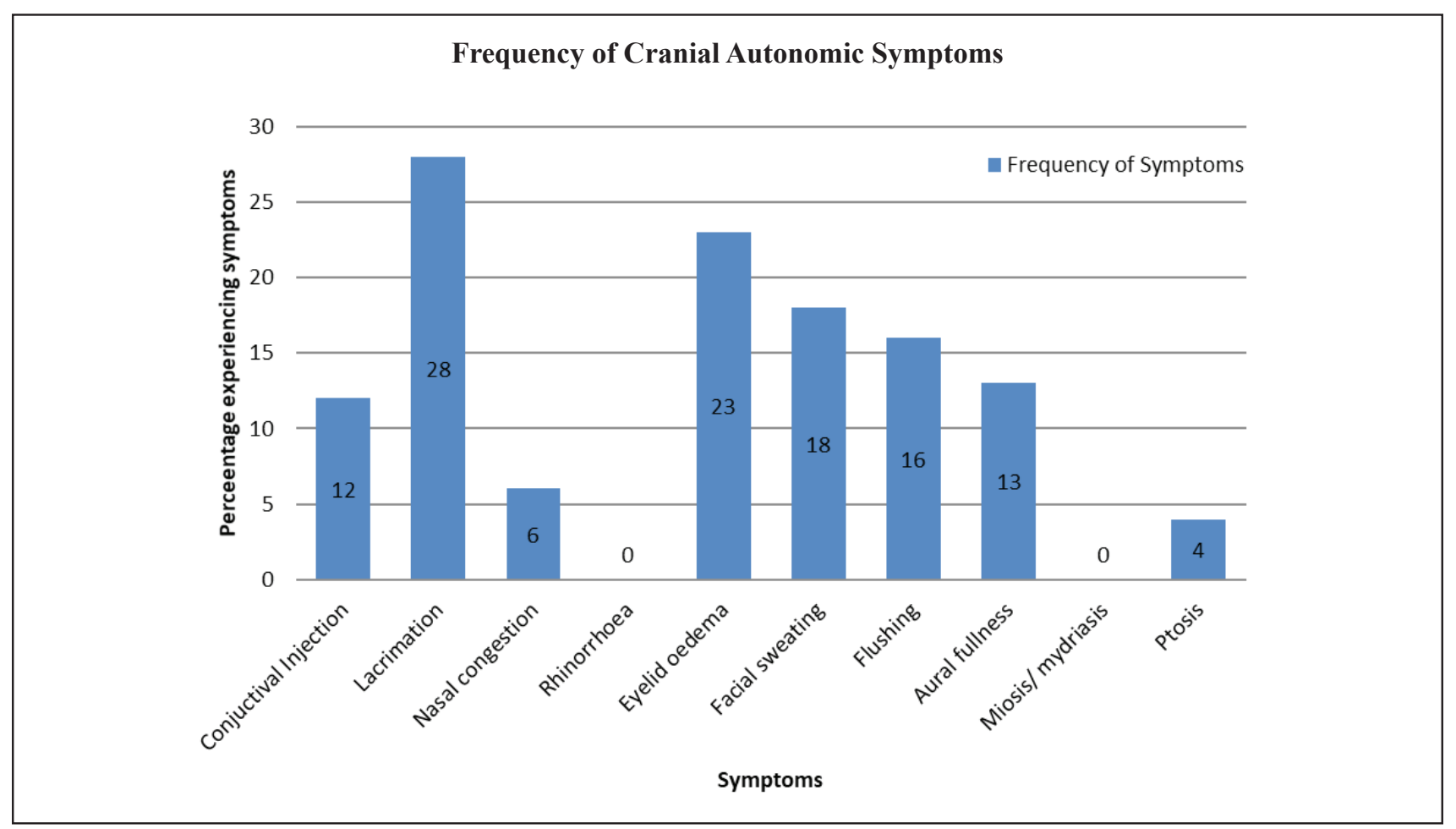

Figure 1: Frequency of each cranial autonomic symptom (\%).

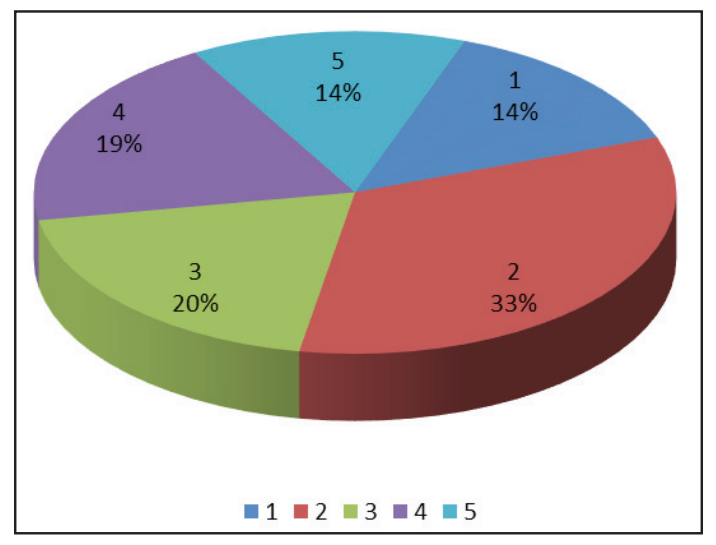

Figure 2: Distribution of cranial autonomic symptoms (in percentage) in migraineurs. Around fifty percent of migraineurs have not more than two symptoms. 


\begin{tabular}{|c|c|c|c|}
\hline Characteristics & $\begin{array}{c}\text { CAS* Present }(\mathrm{N}=36) \\
n(\%)\end{array}$ & $\begin{array}{c}\text { CAS* Absent }(\mathrm{N}=14) \\
\text { n }(\%)\end{array}$ & $\begin{array}{c}\text { Total }(\mathrm{N}=50) \\
\mathrm{n}(\%)\end{array}$ \\
\hline \multicolumn{4}{|l|}{ Gender } \\
\hline Male & $10(27.8)$ & $4(28.6)$ & $14(28)$ \\
\hline Female & $26(72.2)$ & $10(71.4)$ & $36(72)$ \\
\hline \multicolumn{4}{|c|}{ Age (in completed years) } \\
\hline $15-25$ & $15(41.7)$ & $6(42.9)$ & $21(42)$ \\
\hline $26-35$ & $13(36.1)$ & $4(28.6)$ & $17(34)$ \\
\hline $36-50$ & $8(22.2)$ & $4(28.6)$ & $12(24)$ \\
\hline Mean \pm SD & $27.3 \pm 8.5$ & $28.8 \pm 8.2$ & $27.7 \pm 8.3$ \\
\hline \multicolumn{4}{|l|}{ Residence } \\
\hline Urban & $17(47.2)$ & $6(42.9)$ & $23(46)$ \\
\hline Rural & $19(52.8)$ & $8(57.1)$ & $27(54)$ \\
\hline \multicolumn{4}{|l|}{ Religion } \\
\hline Hindu & $32(88.9)$ & $13(92.9)$ & $45(90)$ \\
\hline Muslim & $4(11.1)$ & $1(7.1)$ & $5(10)$ \\
\hline
\end{tabular}

*CAS - Cranial autonomic symptoms

Table 1: Demographic and clinical profile of migraine patients with and without CAS.

\begin{tabular}{|c|c|c|c|c|}
\hline Characteristics & $\begin{array}{c}\text { CAS Present }(\mathrm{N}=36) \\
n(\%)\end{array}$ & $\begin{array}{c}\text { CAS Absent }(\mathrm{N}=14) \\
\text { n }(\%)\end{array}$ & Pvalue $^{\#}$ & $\begin{array}{c}\text { Total }(\mathrm{N}=50) \\
\mathrm{n}(\%)\end{array}$ \\
\hline Family history & $10(27.8)$ & $4(28.6)$ & $1.00 *$ & $14(28)$ \\
\hline Premonitory symptoms & $3(60)$ & $2(40)$ & $0.61 *$ & $5(10)$ \\
\hline Aura & $4(66.7)$ & $2(33.3)$ & $1.00 *$ & $6(12)$ \\
\hline \multicolumn{5}{|l|}{ Duration of illness } \\
\hline$<5$ years & $17(47.2)$ & $6(42.9)$ & \multirow{2}{*}{0.78} & $23(46)$ \\
\hline $5-10$ years & $19(52.8)$ & $8(57.1)$ & & $27(54)$ \\
\hline \multicolumn{5}{|c|}{ Frequency of headache attacks } \\
\hline$<5$ per month & $12(33.3)$ & $7(50)$ & \multirow{2}{*}{0.28} & $19(38)$ \\
\hline $5-10$ per month & $24(66.7)$ & $7(50)$ & & $31(62)$ \\
\hline \multicolumn{5}{|l|}{ Location of headache } \\
\hline Hemicranial & $29(80.6)$ & $9(64.3)$ & \multirow{4}{*}{0.56} & $38(76)$ \\
\hline Bifrontal & $1(2.8)$ & $0(0)$ & & $1(2)$ \\
\hline Global & $4(11.1)$ & $3(21.4)$ & & $7(14)$ \\
\hline Occipital & $2(5.6)$ & $2(14.3)$ & & $4(8)$ \\
\hline \multicolumn{5}{|l|}{ Severity of pain (VAS) } \\
\hline Moderate & $8(22.2)$ & $7(50)$ & \multirow{2}{*}{0.09} & $15(30)$ \\
\hline Severe & $28(77.8)$ & $7(50)$ & & $35(70)$ \\
\hline \multicolumn{5}{|l|}{ Associated symptoms } \\
\hline Nausea & $30(83.3)$ & $12(85.7)$ & 0.83 & $42(84)$ \\
\hline Vomiting & $23(63.9)$ & $9(64.3)$ & 0.98 & $32(64)$ \\
\hline Photophobia & $31(86.1)$ & $13(92.9)$ & $0.67 *$ & $44(88)$ \\
\hline Phonophobia & $29(80.6)$ & $10(71.4)$ & $0.71 *$ & $39(78)$ \\
\hline Vertigo & $8(22.2)$ & $4(28.6)$ & $0.72 *$ & $12(24)$ \\
\hline \multicolumn{5}{|l|}{ Aggravating factors } \\
\hline Sunlight & $32(88.9)$ & $13(92.9)$ & $1.00 *$ & $45(90)$ \\
\hline Noise & $26(72.2)$ & $11(78.6)$ & $0.73 *$ & $37(74)$ \\
\hline Fasting & $13(36.1)$ & $5(35.7)$ & 0.98 & $18(36)$ \\
\hline Travel & $5(13.9)$ & $4(28.6)$ & 0.41 & $9(18)$ \\
\hline Stress & $6(16.7)$ & $3(21.4)$ & $1.00 *$ & $9(18)$ \\
\hline
\end{tabular}

\#chi square test, *exact sig

Table 2: Clinical characteristics of headache in patients of migraine with and without CAS. 


\section{Discussion}

$72 \%$ of patients with migraine in the present study had at least one or more CAS during the headache attacks, suggesting that CAS in Indian patients with migraine is relatively common. D Danno et al. also concluded that around $42.4 \%$ of migraineurs have 1 or more CAS. ${ }^{21}$ Similar to the present study, lacrimation was the most common CAS as reported by D Danno et al (13.9\%).

First study of CAS in migraine was done by Blau in 1970. They examined microscopically conjunctiva, lip, tongue, and nail fold vessels in 35 migrainous subjects between attacks. They found that the vessels were normal, but 12 out of the $35(34.3 \%)$ showed intravascular redcell aggregation, a substantially higher proportion than in controls. The conjunctiva was edematous in 3 of the 11 patients while no changes were observed in tongue vessels. They concluded from the study that the vascular responses in migraine do exist and are usually bilateral. ${ }^{22}$ In our study also an obvious vascular response in the form of conjunctival injection was present in $24 \%$ of patients.

Obermann $\mathrm{M}$ et al. $^{7}$ in their study in Germany demonstrated that the unilateral autonomic symptoms in patients with migraine have been widely underestimated in the past as one out of four migraine patients regularly experiences one or more unilateral autonomic symptoms during their headache attack. In their population-based study, 841 subjects had migraine, out of which 226 reported accompanying unilateral autonomic symptoms (26.9\%). Contrary to this study, the substantially high percentage (74\%) of CAS is possibly being explained as our study is hospital based and recruitment of patients was done from headache clinics.

Barbanti $\mathrm{P}$ et al. in their systematic trial, done at a tertiary referral center in Rome, Italy ${ }^{14}$ found that unilateral autonomic symptoms were present in $45.8 \%$ patients, almost double what was found in the study of Obermann $M$ et al.

Riesco N. et al in their study among patients of migraine recruited in headache clinic reported $82 \%$ of the patients having at least one of cranial parasympathetic autonomic symptom. ${ }^{12}$ Similarly a high proportion (74\%) of CAS was recorded in the present study possibly because in both the studies recruitment of migraine patients was done through headache clinic itself.

As we use better-defined criteria in the clinical settings and more effective interviewing techniques, the prevalence of migraine-associated symptoms is usually higher in clinic-based studies than in population-based studies. We also cannot exclude the possibility of selection bias in hospital-based studies when the patients with more severe headache and more symptoms are recruited. Another possible consideration of the relatively high frequency of CAS in the present sample of migraine patients is a relative apprehension regarding CAS leading to more consultation for these symptoms in the hospital than those of milder form of migraine patients.

In the present study it was found that stronger the severity of pain, more likely is the development of CAS in migraine patients. So, it can be postulated that the pain intensity may correlate positively to the development of cranial autonomic symptoms. This association of severity of pain was also demonstrated by Dora B et al and Barbanti $\mathrm{P}$ et al. ${ }^{13,23}$ Migraine headaches sometimes mimics like cluster headache due to severity of pain and strict unilaterality, therefore Solomon $\mathrm{S}$ et al. proposed the term 'migraine-cluster headache syndrome'. ${ }^{24}$ The pathophysiology behind the CAS in migraine is explained by trigemino-vascular reflex involvement as in TACs like cluster headache. ${ }^{25}$

Barbanti P et al. in their headache clinic based study including 757 patients of migraine denoted that $37.4 \%$ of migraine patients have at least one of unilateral CAS during headache attack. ${ }^{13}$ They showed that Ocular symptoms like lacrimation, conjunctival injection and eyelid edema alone occurred in $61.8 \%$ of unilateral CAS followed by nasal symptoms like nasal congestion and rhinorrhea. ${ }^{13}$ They postulated from the study that the origin of CAS in migraine patients is from trigemino-vascular system as they found that the clinical phenotype of migraine with unilateral CAS reveals not only an intense peripheral trigeminal activation as suggested by pain features, but also by a central sensitization, as indicated by its accompanying symptoms. They also concluded from the study that the migraine with unilateral cranial autonomic symptoms is characterized by a longer attack duration, more strictly unilateral and severe headache and more frequent allodynia and photophobia than migraine without CAS.

Gupta $\mathrm{R}$ et al did a similar hospital-based study of CAS in migraine from north India. ${ }^{17}$ They found that CAS was present in $73.1 \%$ of subjects and these symptoms were ipsilateral to headache while strictly unilateral cranial autonomic symptoms were reported by only $32 \%$ of patients. They concluded that CAS are frequent in migraineurs and are more common in patients with long duration of illness and longer headache episodes. These CAS were probably explained by a hyperactive efferent arm of trigeminal autonomic reflex. Thus the observed phenotypic differences between the two groups of migraine with CAS and without CAS possibly can be explained by connections of trigeminal nucleus with the locus coeruleus and dorsal raphe nucleus.

Riesco N. et al studied only five cranial autonomic symptoms (parasympathetic) and graded them in three categories in patients of chronic migraine. ${ }^{12}$ Similar to the present study, Riesco $\mathrm{N}$ et al also found lacrimation as the most frequent CAS, which were reported by almost half 
of their patients, while sensation of ear fullness and nasal congestion and/or rhinorrhea were described in fewer than $30 \%$ of cases. They concluded that mild cranial autonomic parasympathetic symptoms are not the exception but the rule in chronic migraine patients. This study supported the hypothesis that the activation of the parasympathetic arm of the trigeminal vascular symptoms plays a role in the pathophysiology of pain and presence of CAS in primary headaches specifically in migraine. Supporting this hypothesis, Maizels M et al used intranasal application of lidocaine, which blocked the sphenopalatine ganglion, and aborted migraine within 15 minutes in $36 \%$ of patients in a studied population. ${ }^{26}$ Based on the same rationale Yarnitsky et al. showed that patients with parasympathetic CAS were more likely to experience pain relief by lidocaine than patients without these symptoms, with a pain reduction of $53 \%$ and $15 \%$, respectively. ${ }^{27}$

There are many limitations of this study like small sample size, recruitment of patients from headache clinics where more severe and disabling headache patients are consulted and of course the problem of selection bias cannot be excluded. Furthermore, we can also compare these patients of migraine with CAS + group with other TACs like cluster headache for better understanding of the pathophysiology CAS in migraine.

\section{Conclusion}

Therefore, to conclude, cranial autonomic symptoms are not uncommon in migraineurs as underestimated in the past. More severe headache is more likely associated with the development of CAS. As we know that a substantial phenotypic heterogeneity is an attribute of migraine, this type of analysis may help to identify a homogeneous phenotype within the patients of migraine for a better understanding of clinical signs and symptoms, their management protocols and future prognosis.

\section{Conflict of Interest: None \\ Source(s) of support: None}

\section{References}

1. Stovner L, Hagen K, Jensen R, Katsarava Z, Lipton $\mathrm{RB}$, Scher AI, et al. The global burden of headache: A documentation of headache prevalence and disability worldwide. Cephalalgia. 2007;27:193-210. https:// doi.org/10.1111/j.1468-2982.2007.01288.x

2. Goadsby PJ, Lipton RB, Ferrari MD. Migraine current understanding and treatment. N Engl J Med. 2002 Jan;346(4):257-70.https://doi.org/10.1056/ NEJMra010917

3. Headache Classification Committee of the International Headache Society (IHS). The international classification of headache disorders, 3rd edition (beta version). Cephalalgia. 2018;38:1-211. https://doi.org/10.1177/0333102417738202

4. Peroutka SJ. Migraine:A chronic sympathetic nervous system disorder. Headache. 2004; 44(1):53-64. https://doi.org/10.1111/j.1526-4610.2004.04011.x

5. Yakinci C, Mungen B, Er H, Durmaz Y, Karabiber $\mathrm{H}$. Autonomic nervous system function in childhood migraine. Pediatr Int. 1999;41:529-33. https://doi. org/10.1046/j.1442-200x.1999.01101.x

6. Shechter A, Stewart WF, Silberstein SD, Lipton RB. Migraine and autonomic nervous system function: A population-based, case-control study. Neurology. 2002;58(3):422-7.https://doi.org/10.1212/ wnl.58.3.422

7. Obermann M, Yoon MS, Dommes P, Kuznetsova J, Maschke M, Weimar C, et al. Prevalence of trigeminal autonomic symptoms in migraine: A populationbased study. Cephalalgia. 2007;27:504-9. https://doi. org/10.1111/j.1468-2982.2007.01316.x

8. Benjelloun H, Birouk N, Slaoui I, Coghlan L, Bencheikh BO, Jroundi I et al. Autonomic profile of patients with migraine. Neurophysiol Clin. 2005;35:127-34.https://doi.org/10.1016/s00033928(04)00020-4

9. Pogacnik T, Sega S, Pecnik B, Kiauta T. Autonomic function testing in patients with migraine. Headache. 1993;33:545-50. https://doi. org/10.1111/j.1526-4610.1993.hed3310545.x

10. Goadsby PJ, Charbit AR, Andreou AP, Akerman S, Holland PR. Neurobiology of migraine. Neuroscience 2009;161:327-41.https://doi.org/10.1016/j. neuroscience.2009.03.019

11. Kaube H, Katsarava Z, Przywara S, Drepper J, Ellrich J, Diener H C. Acute migraine headache: Possible sensitization of neurons in the spinal trigeminal nucleus? Neurology. 2002 Apr;58(8):1234-8. https:// doi.org/10.1212/wnl.58.8.1234

12. Riesco N, Pérez-Alvarez AI, Verano L, GarciaCabo C, Martinez-Ramos J, Sanchez-Lozano P, et al. Prevalence of cranial autonomic parasympathetic symptoms in chronic migraine: Usefulness of a new scale. Cephalalgia. 2016;36:346-50. https://doi. org/10.1177/0333102415593087

13. Barbanti P, Aurilia C, Dall'Armi V, Egeo G, Fofi L, Bonassi S. The phenotype of migraine with unilateral cranial autonomic symptoms documents increased peripheral and central trigeminal sensitization. A case series of 757 patients. Cephalalgia. 2016;36:133440.https://doi.org/10.1177/0333102416630579

14. Barbanti P, Fabbrini G, Pesare M, Vanacore N, Cerbo R. Unilateral cranial autonomic symptoms in migraine. Cephalalgia. 2002;22:256-9. https://doi. org/10.1046/j.1468-2982.2002.00358.x 


\section{Qavi et al}

15. Avnon Y, Nitzan M, Sprecher E, Rogowski Z, Yarnitsky D. Different patterns of parasympathetic activation in uni- and bilateral migraineurs. Brain. 2003; 126:1660-70. https://doi.org/10.1093/brain/ awg 158

16. Kaup AO, Mathew NT, Levyman C, Kailasam J, Meadors LA, Villarreal SS. 'Side locked' migraine and trigeminal autonomic cephalalgias: Evidence for clinical overlap. Cephalalgia. 2003;23:43-9. https:// doi.org/10.1046/j.1468-2982.2003.00451.x

17. Gupta R, Bhatia MS. A report of cranial autonomic symptoms in migraineurs. Cephalalgia. 2007;27:228. https://doi.org/10.1111/j.1468-2982.2006.01237.x

18. Gelfand AA, Reider AC, Goadsby PJ. Cranial autonomic symptoms in pediatric migraine are the rule, not the exception. Neurology. 2013;81:431-6. https://doi.org/10.1212/WNL.0b013e31829d872a

19. Eross E, Dodick D, Eross M. The Sinus, Allergy and Migraine Study (SAMS). Headache. 2007;47:213-24. https://doi.org/10.1111/j.1526-4610.2006.00688.x

20. Schreiber CP, Hutchinson S, Webster CJ, Ames M, Richardson MS, Powers C. Prevalence of migraine in patients with a history of self-reported or physician-diagnosed "sinus" headache. Arch Intern Med. 2004;164:1769-72. https://doi.org/10.1001/ archinte.164.16.1769

21. Danno D, Wolf J, Ishizaki K, Kikui S, Yoshikawa H, Takeshima T. Cranial autonomic symptoms of migraine in Japan: Prospective study of 373 migraine patients at a tertiary headache center. Headache. 2020 Sep;60(8):1592-1600. https://doi.org/10.1111/ head. 13888

22. Blau JN, Davis E. Small blood-vessels in migraine. Lancet. 1970;740-2. https://doi.org//10.1016/S01406736(70)90219-9

23. Dora B. Migraine with cranial autonomic features and strict unilaterality. Cephalalgia. 2003; 23:561-2. https://doi.org//10.1046/j.1468-2982.2003.00584.x

24. Solomon S, Karfunkel P, Guglielmo KM. Migrainecluster headache syndrome. Headache. 1985;25:2369.https://doi.org/10.1111/j.1526-4610.1985. hed2505236.x

25. Lai TH, Fuh JL, Wang SJ. Cranial autonomic symptoms in migraine: Characteristics and comparison with cluster headache. J Neurol Neurosurg Psychiatry. 2009;80:1116-9. https://doi. org/10.1136/jnnp.2008.157743

26. Maizels M, Geiger AM. Intranasal lidocaine formigraine: A randomized trial and open-label follow-up. Headache. 1999;39:543-51. https://doi. org/10.1046/j.1526-4610.1999.3908543.x

27. Yarnitsky D, Goor-Aryeh I, Bajwa ZH, Ransil BI, Cutrer FM, Sottile A, et al. Possible parasympathetic contributions to peripheral and central sensitization during migraine. Headache. 2003;43:704-14. https:// doi.org/10.1046/j.1526-4610.2003.03127.x 